\title{
Automated collection and dissemination of ionospheric data from the digisonde network
}

\author{
B. W. Reinisch, I. A. Galkin, G. Khmyrov, A. Kozlov, and D. F. Kitrosser \\ Environmental, Earth, and Atmospheric Sciences Department, Center for Atmospheric Research, University of \\ Massachusetts, Lowell, USA
}

\begin{abstract}
The growing demand for fast access to accurate ionospheric electron density profiles and ionospheric characteristics calls for efficient dissemination of data from the many ionosondes operating around the globe. The global digisonde network with over 70 stations takes advantage of the Internet to make many of these sounders remotely accessible for data transfer and control. Key elements of the digisonde system data management are the visualization and editing tool SAO Explorer, the digital ionogram database DIDBase, holding raw and derived digisonde data under an industrial-strength database management system, and the automated data request execution system ADRES.
\end{abstract}

\section{Introduction}

Ionosondes used to be the workhorse of ionospheric radio research, and until the 1950s were the only supplier of reliable ionospheric data. Then in situ observations on rockets and satellites became available, remote sensing with UHF and VHF incoherent and coherent scatter radars provided great details at selected locations, and measurements on the ground and on satellites of radio signals from topside satellites determined the large scale electron density distribution in the ionosphere using tomography and limb-scanning techniques. Ionosondes continue to play an important role because they provide accurate vertical electron density profiles as function of time at many locations around the globe. This paper describes the networking of digisondes, the types of results obtained, their databasing, and the real time access. There are other digital ionosondes operating at various sites, some of them producing similar data as the Digisonde, like the KEL sounder, the Advanced Ionospheric Sounder or Dynasonde, and the CADI sounder. We describe the digisonde data collection and dissemination system as an example, because it is believed to be the largest and most advanced such system in routine operation.

Correspondence to: B. W. Reinisch

(bodo_reinisch@uml.edu)

\section{Data from the ionosonde network}

Global coverage of the ionosphere with ionosondes became reality with the International Geophysical Year in 19571958, and the necessity for standardized interpretation and scaling of ionograms became immediately apparent. URSI established a Worldwide Sounding Committee (WWSC), which issued the Handbook of Ionogram Interpretation and Reduction, prepared by Piggott and Rawer in 1961 and revised in 1972 (Piggott and Rawer, 1972). In 1969 the Ionosonde Network Advisory Group (INAG), with Roy Piggott as chairman, replaced the WWSC. Today INAG, currently under the chairmanship of Terence Bullett, is responsible for maintaining uniform ionogram reduction rules. For a long time the usefulness of the ionosonde network was handicapped by the limited data accessibility. Usually only the hourly ionograms were scaled, and the reduced values were hand recorded. The World Data Centers (WDC) prescribed a standard format for the monthly tabulation of ionospheric characteristics that allowed the systematic archiving of the data. While originally designed for the archiving of only hourly values, the URSI Ionospheric Informatics Working Group (IIWG), with Bodo Reinisch as the chairman, developed a more flexible format that permits the archiving of irregular time series data (Gamache and Reinisch, 1991; Reinisch, 1998a). This format is used today in the world data centers, where the data can be accessed with the Space Physics Interactive Data Resource (SPIDR) developed by the National Geophysical Data Center in Boulder, CO (Conkright, 1999). To facilitate the archiving and exchange of reduced data of individual ionograms the IIWG developed the Standard Archiving Output (SAO) format for the ionogram characteristics (Reinisch, 1998b). This format, recommended by URSI for all reduced ionogram data, is now widely used for data from different type ionosondes. The Digisonde network (Fig. 1) is using the SAO format for the automatically scaled data during the last 10 years. 


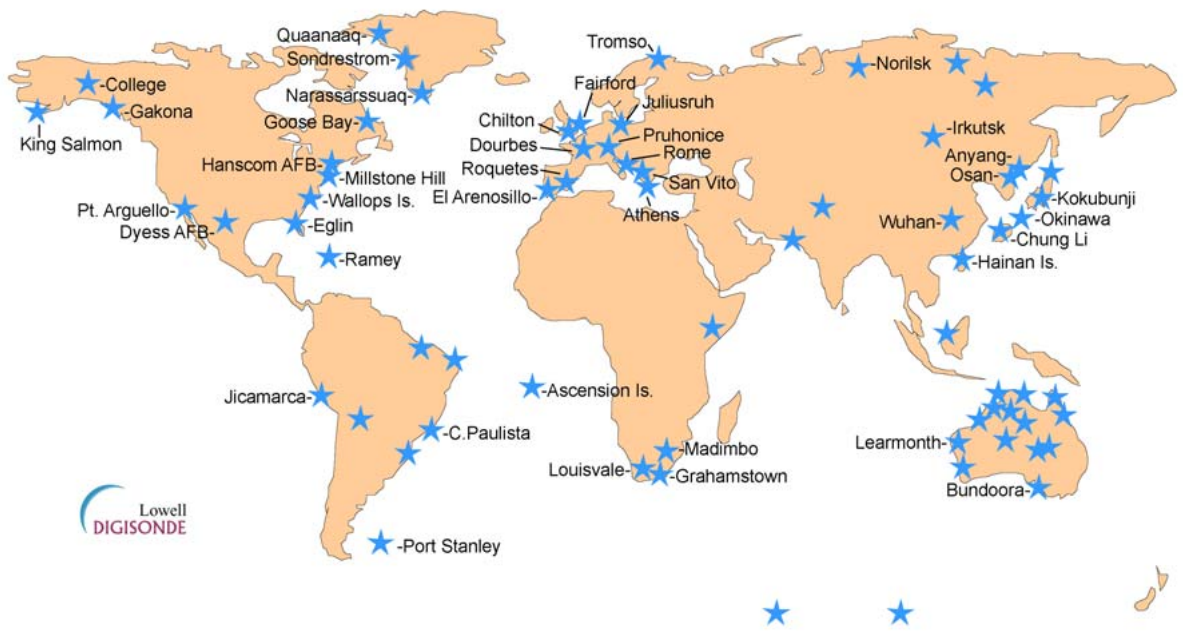

Fig. 1. The global digisonde network. Data from unnamed stations currently are not available via Internet or DIDBase access.

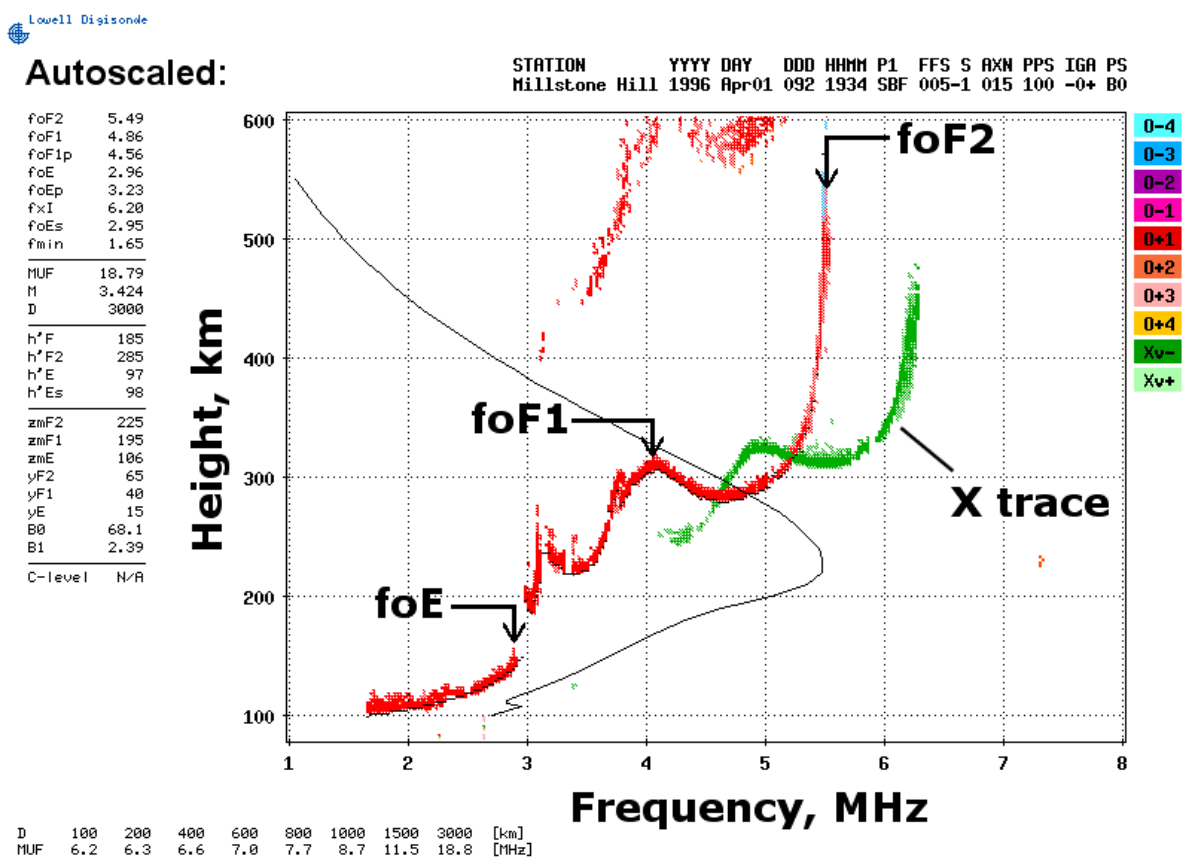

Fig. 2. Real time autoscaled daytime ionogram at Millstone Hill, listing the most important characteristics on the left.

\section{Real time data}

Many space weather applications require real time access to the ionospheric characteristics from a large set of ionosonde stations (Galkin et al., 1999). An early generation of digisondes, the "Digisonde 256" (Bibl and Reinisch, 1978) was designed with this goal in mind. The Digisonde $256 \mathrm{em}-$ ployed algorithms for automated onsite scaling of ionograms (Reinisch and Huang, 1983) and provided modem communications with remote data processing centers for delivery of the scaled data in real-time. In the late 1980s, the US Air Force Weather Service deployed $\sim 20$ Digisondes 256 in their DISS network to support the USAF Space Forecast Center operations (Reinisch, 1996a; Buchau et al., 1995) feeding real time data to the PRISM and GAIM modeling projects (Daniell et al., 1995; Sojka et al., 2003) Another special network of 15 digisondes, using the second-generation Digisonde Portable Sounders (DPS) (Reinisch, 1996b) operates in Australia, providing ionospheric characteristics and electron density profiles to update the Real Time Ionospheric Models (RTIMs) of electron density distribution (Barnes et al., 2000; Reinisch et al., 1997). The RTIM densities are used by various Australian defense projects such as the Jindalee Over-the-horizon Radar Network (JORN) and Jindalee Facility at Alice Springs (JFAS). These two special digisonde networks are maintained by defense organizations that employ dedicated communication links and impose certain restrictions on public access to the data. Meanwhile, an increasing 


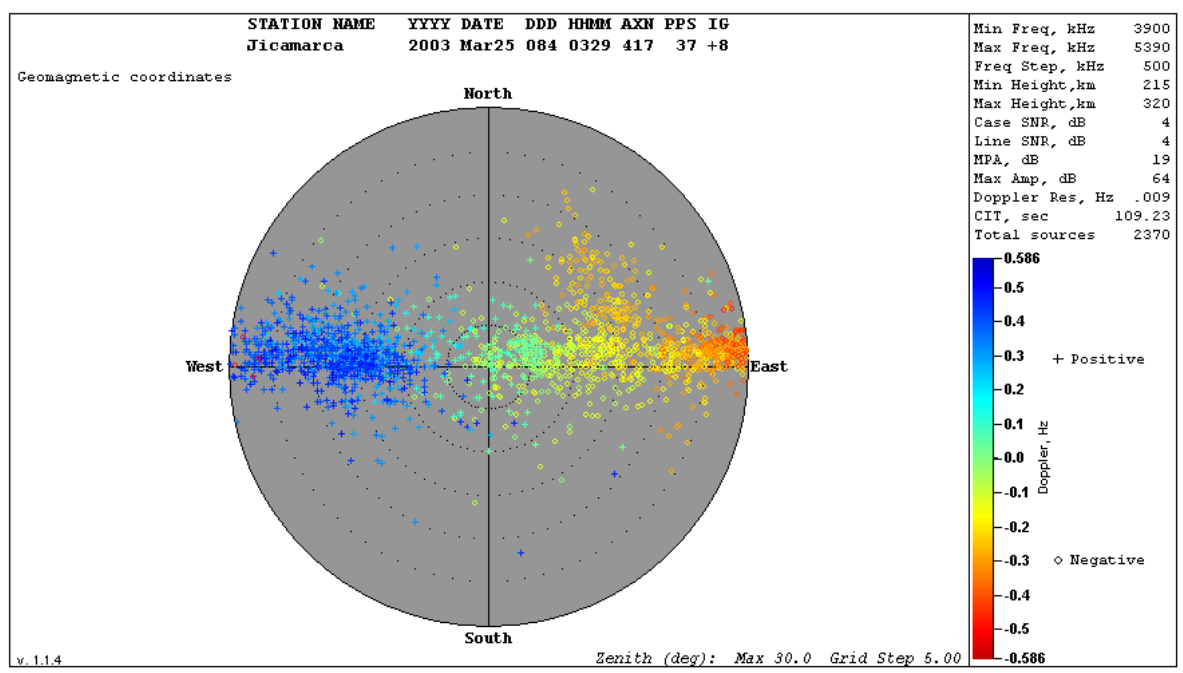

Fig. 3. Real time skymap at Jicamarca at 22:29 LT on 22 March 2003 showing the echo location and Doppler frequencies (color coded) for F-region echoes at frequencies between 3.9 and $5.4 \mathrm{MHz}$.

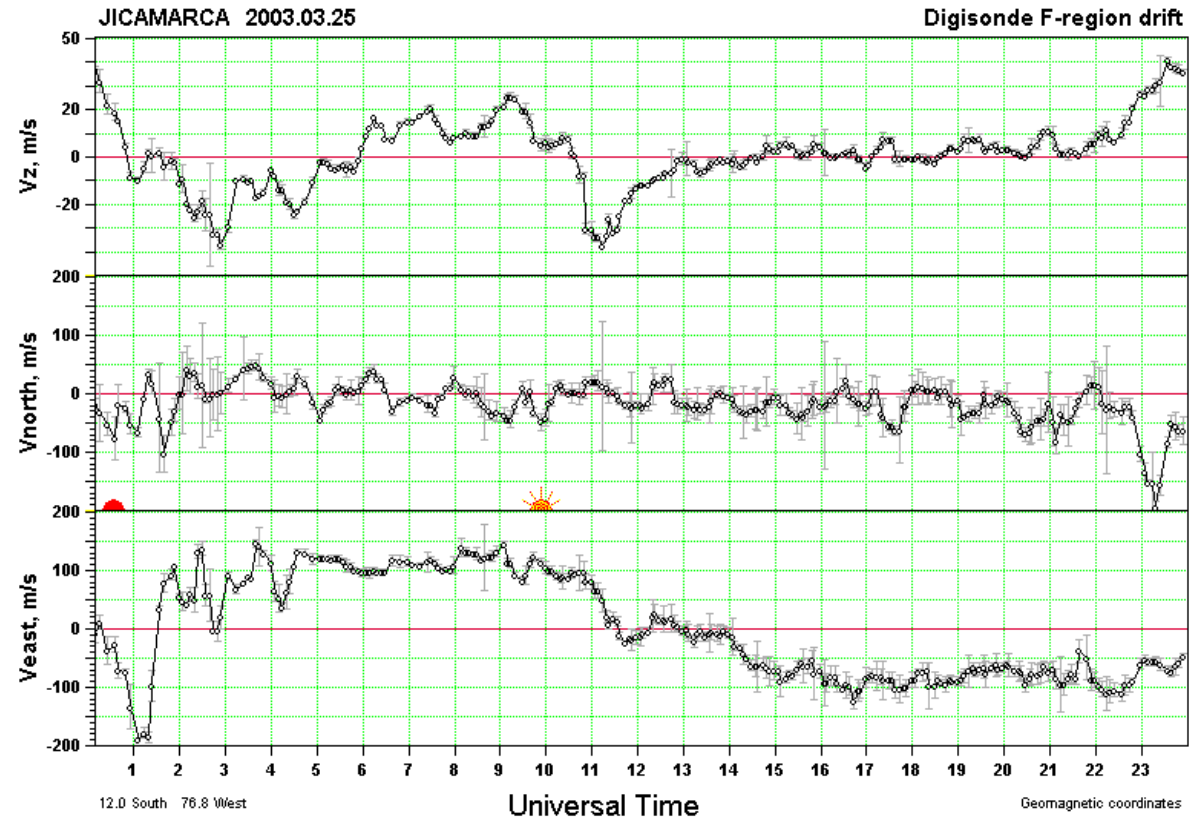

Fig. 4. Real time vertical and horizontal drift components as function of time at Jicamarca for 25 March 2003. The error bars are shown in gray. Sunset and sunrise are indicated in the central panel.

number of research digisondes discover advantages of the Internet as an inexpensive solution to the problem of rapid data dissemination. Using standard Internet protocols, it is possible not only to establish the real time data stream to remote processing centers, but also to publish both latest and retro data at the digisonde location using the WWW server that is included in the standard digisonde software since the late 1990s.

Modern online digisondes publish a variety of ionospheric data presentations in real-time on the WWW. Figures 2-5 show samples of the published "latest" images that are available within a minute after the sounding is complete; HTML documents with the latest images are refreshed automatically on the local client computer so that they can be monitored at remote locations. Figure 2 shows a typical daytime midlatitude ionogram recorded at Millstone Hill, Massachusetts, together with the autoscaled ionospheric characteristics (left side) and a table of Maximum Usable Frequencies calculated for a number of preset path distances (bottom). Figure 3 presents an example of a latest skymap, a plot of calculated echo locations for an automatically selected subset of frequencies and heights in the F-region of the ionosphere. The skymap in Fig. 3 was taken at Jicamarca at 22:29 LT on 22 March 2003 during the night-time eastward drift of plasma 


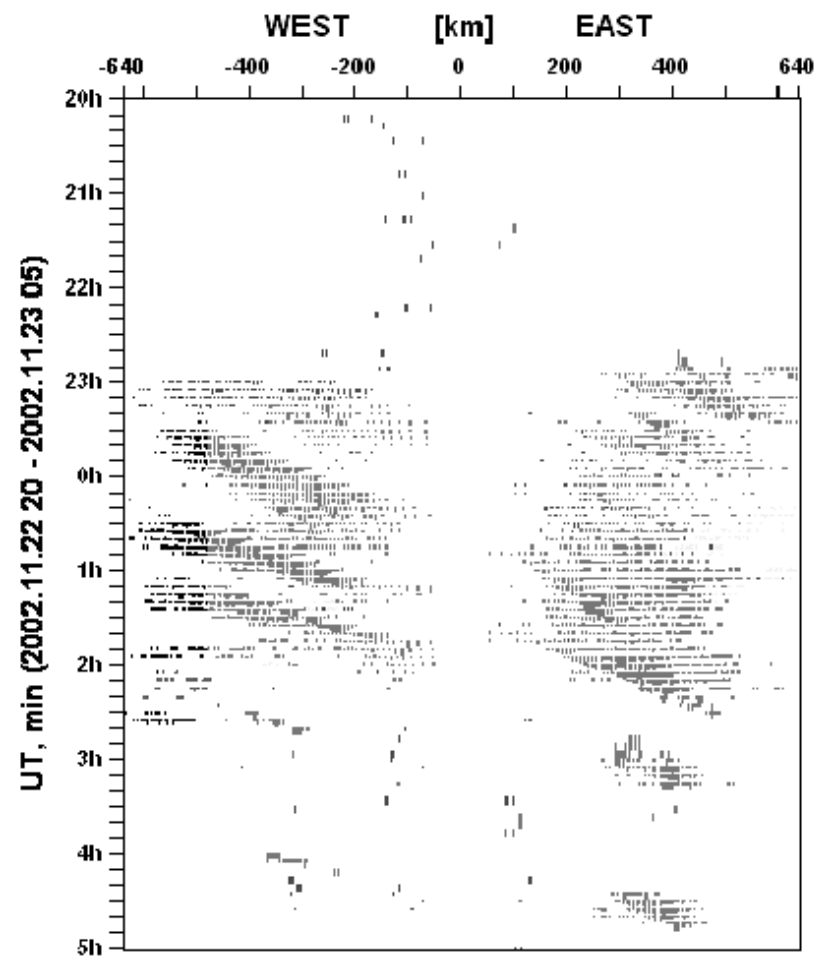

Fig. 5. Directogram at Cachimbo for $22 / 23$ November 2004 shows as function of time the approximate location of irregularities seen by the multi-beam ionograms. Each horizontal line presents data from one ionogram.

irregularities along the magnetic equator; the color coding is used to indicate the Doppler shift of the sounding frequency. In addition to the skymaps indicating echo locations, the bulk motion of plasma across the station location can be calculated from the digisonde drift mode data. Figure 4 presents a sample of daily drift velocity plots (updated with the realtime data) showing vertical and horizontal components as a function of time. The error bars on the given values represent the degree to which the motions in the plasma can be considered as a bulk motion. Finally, Fig. 5 gives an example of a directogram, a daily plot of locations of the irregularities in the ionosphere derived from the multi-beam ionograms showing echo directions. Directograms are useful for quick identification of spread $\mathrm{F}$ conditions and characterization of the preferred motion of irregularities in the ionosphere.

\section{Digisonde online databasing and quality control}

With increasing number of applications relying on the "ground truth" extracted from ionograms, a staggering task of quality control and verification of the autoscaled data has emerged. While increasing attention is placed on development of techniques for automated quality control of autoscaling results (e.g. Conkright and McNamara, 1996), it is critical for many research and applied projects to verify and/or edit the derived ionospheric characteristics by human inspection. We placed the human verification process into the framework of computer technologies that are convenient for both data verification experts (scalers) and the end users. Demanding the highest possible degree of accuracy for the ionogram-derived characteristics, this system now sets a new standard for management of ionosonde data.

Three key elements of the digisonde data management system are: (1) the "SAO Explorer", a digisonde data visualization and editing tool, (2) "DIDBase" (Digital Ionogram Database) holding raw and derived digisonde data under an industrial-strength database management system, and (3) "ADRES" (Automated Data Request Execution System) capable of accepting the "ground truth" requests for particular periods of time and locations and actively managing the process of acquiring, verifying, and reporting the requested data.

\subsection{DIDBase}

While the WDC SPIDR remains the major tool for accessing a great variety of geo, solar and space physics datasets, it was not designed to provide its users with the capability of interactively validating the autoscaled ionogram data. Arranging such validation process necessarily involves provision of raw ionogram data for reference, mating the database to an ionogram editing tool, and allowing online submissions of the edited/verified data back to the database. The need for a small, dedicated project was identified to establish an interactive, concurrent, read/write access to an archive of ionograms and scaled data. A pilot DIDBase project of this kind was started in 2001 at UMASS Lowell for the data collected from the network of 44 digisonde sounders (see Fig. 1 for the locations of contributing stations). Currently DIDBase holds $\sim 80$ GB of data and accepts real-time and near real-time submissions from 38 digisondes listed in Table 1.

The central piece of the DIDBase is a relational DBMS Firebird 1.0 chosen for its reliability and minimal administration expense. The database structure is designed to include the binary digisonde ionograms data together with multiple scaling records for each ionogram. By relaxing the conventional scenario "one ionogram - one set of derived characteristics", the DIDBase creates new possibilities for multiple trace identifications, storage of alternative ionogram interpretations, and a variety of comparative studies of the automated ionogram processing quality. As an example, the new technology makes it possible to store several simultaneously observed auroral E layers, which is of interest for high latitude ionospheric research. Although multiple scalings (interpretations) for a given ionograms are stored, the DIDBase maintains a single subset of preferably used ionospheric characteristics for each ionogram, which can be quickly accessed by the end users looking just for the "best" ionogram interpretation. A hierarchy of expert ranks and quality flags is used to automatically select one best value among existing versions. 
Table 1. Online digisonde stations currently providing real time data to DIDBase.

\begin{tabular}{|c|c|c|c|c|}
\hline URSI code & Station name & Latitude & Longitude & Model \\
\hline AN438 & ANYANG & 37.4 & 127.0 & D256 \\
\hline ASO0Q & ASCENSION ISLAND & -8.0 & 345.6 & DISS (D256) \\
\hline AT138 & ATHENS & 38.0 & 23.5 & DPS \\
\hline BV53Q & BUNDOORA & -37.7 & 145.1 & DPS \\
\hline $\mathrm{CO} 764$ & COLLEGE & 64.9 & 212.0 & DISS (D256) \\
\hline $\mathrm{CAJ} 2 \mathrm{M}$ & CACHOEIRA PAULISTA & -23.2 & 314.2 & D256 \\
\hline DB049 & DOURBES & 50.1 & 4.6 & D256 \\
\hline DS932 & DYESS AFB & 32.4 & 260.2 & DISS (D256) \\
\hline EG931 & EGLIN AFB & 30.4 & 273.2 & DISS (D256) \\
\hline EA036 & EL ARENOSILLO & 37.1 & 353.3 & D256 \\
\hline FF051 & FAIRFORD & 51.7 & 358.5 & DISS (D256) \\
\hline FZA0M & FORTALEZA & -3.8 & 322.0 & DPS \\
\hline GA762 & GAKONA & 62.4 & 215.0 & DPS \\
\hline GSJ53 & GOOSE BAY & 53.3 & 299.7 & DISS (D256) \\
\hline HA419 & HAINAN & 19.4 & 109.0 & DPS \\
\hline GR13L & GRAHAMSTOWN & -33.3 & 26.5 & DPS \\
\hline JI91J & JICAMARCA & -12.0 & 283.2 & DPS \\
\hline JR055 & JULIUSRUH & 54.6 & 13.4 & DPS \\
\hline KS759 & KING SALMON & 58.4 & 203.6 & DISS (D256) \\
\hline LM42B & LEARMONTH & -21.8 & 114.1 & DISS (D256) \\
\hline LV12P & LOUISVALE & -28.5 & 21.2 & DPS \\
\hline MU12K & MADIMBO & -22.4 & 30.9 & DPS \\
\hline MHJ45 & MILLSTONE HILL & 42.6 & 288.5 & DPS \\
\hline NQJ61 & NARSSARSSUAQ & 61.2 & 314.6 & DISS (D256) \\
\hline SN437 & OSAN AFB & 37.1 & 127.0 & DISS (D256) \\
\hline PSJ5J & PORT STANLEY & -51.6 & 302.1 & DPS \\
\hline PQ052 & PRUHONICE & 50.0 & 14.6 & DPS \\
\hline PA836 & PT ARGUELLO & 34.8 & 239.5 & DISS (D256) \\
\hline THJ77 & QAANAAQ & 77.5 & 290.6 & D256 \\
\hline PRJ18 & RAMEY AFB & 18.5 & 292.9 & DISS (D256) \\
\hline RO041 & ROME & 41.9 & 12.5 & DPS \\
\hline EB040 & ROQUETES & 40.8 & 0.3 & D256 \\
\hline SAA0K & SAO LUIS & -2.6 & 315.8 & D256 \\
\hline T139 & SAN VITO & 40.6 & 17.8 & DISS (D256) \\
\hline SMJ67 & SONDRESTROM & 67.0 & 309.1 & DPS \\
\hline TR169 & TROMSO & 69.6 & 19.2 & DPS \\
\hline TUJ2O & TUCUMAN & -26.9 & 294.6 & D256 \\
\hline WP937 & WALLOPS ISLAND & 37.9 & 284.5 & DISS (D256) \\
\hline
\end{tabular}

\subsection{SAO explorer, interactive ionogram analysis tool}

SAO-Explorer is a digisonde data analysis tool used for manual verification and editing of autoscaled digisonde ionograms, as well as a variety of visual presentations of ionograms and derived ionospheric characteristics. It serves best for the in-depth study of particular periods of time or locations where background ionograms are required to aid with data interpretation. The SAO-X workstations are granted both read and write access to the DIDBase allowing full scale, platform-independent, concurrent, remote operations with the archived data over the Internet. Any ionogram interpretation expert can register for write permission and ver- ify/edit the autoscaled data from remote locations. In addition, the SAO-X workstations connect to the SPIDR database to read retrospective ionospheric data that are not available in the DIDBase or locally. Some examples of typical SAO$\mathrm{X}$ outputs are shown in Figs. 6 and 7. The "profilogram" in Fig. 6 shows the vertical electron density distribution as function of time (Reinisch et al., 1994) for one day in October 2003 at the magnetic equator, Cachimbo, Brazil (Abdu et al., 2003) derived from the $\mathrm{N}(\mathrm{h})$ profiles calculated for each ionogram (see Fig. 2). Figure 7 displays three selected (of the 49 available) characteristics at Cachimbo for three consecutive days: foF2, hmF2, and frequency spread QF. 


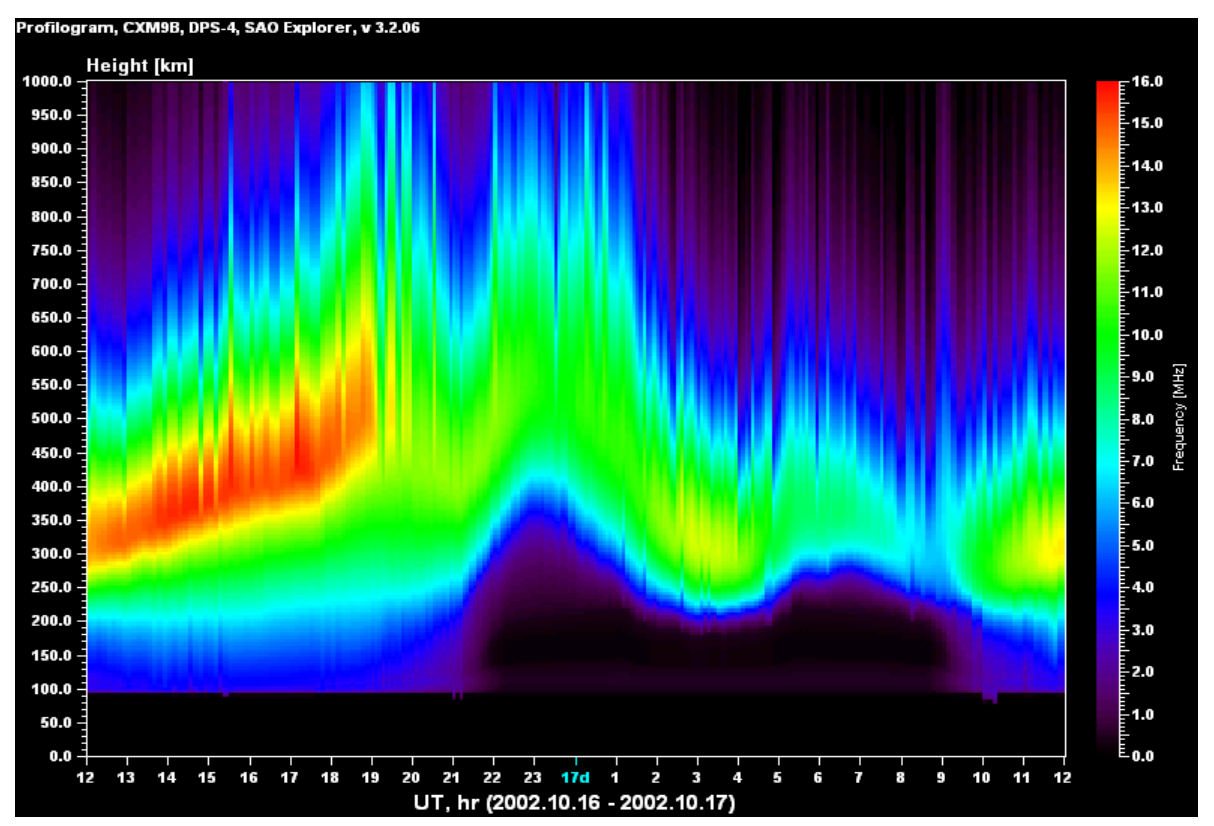

Fig. 6. Profilogram for 16 October 2002 at Cachimbo, Brazil. The plasma frequencies (proportional to $\mathrm{N}^{1 / 2}$ ) are color-coded.

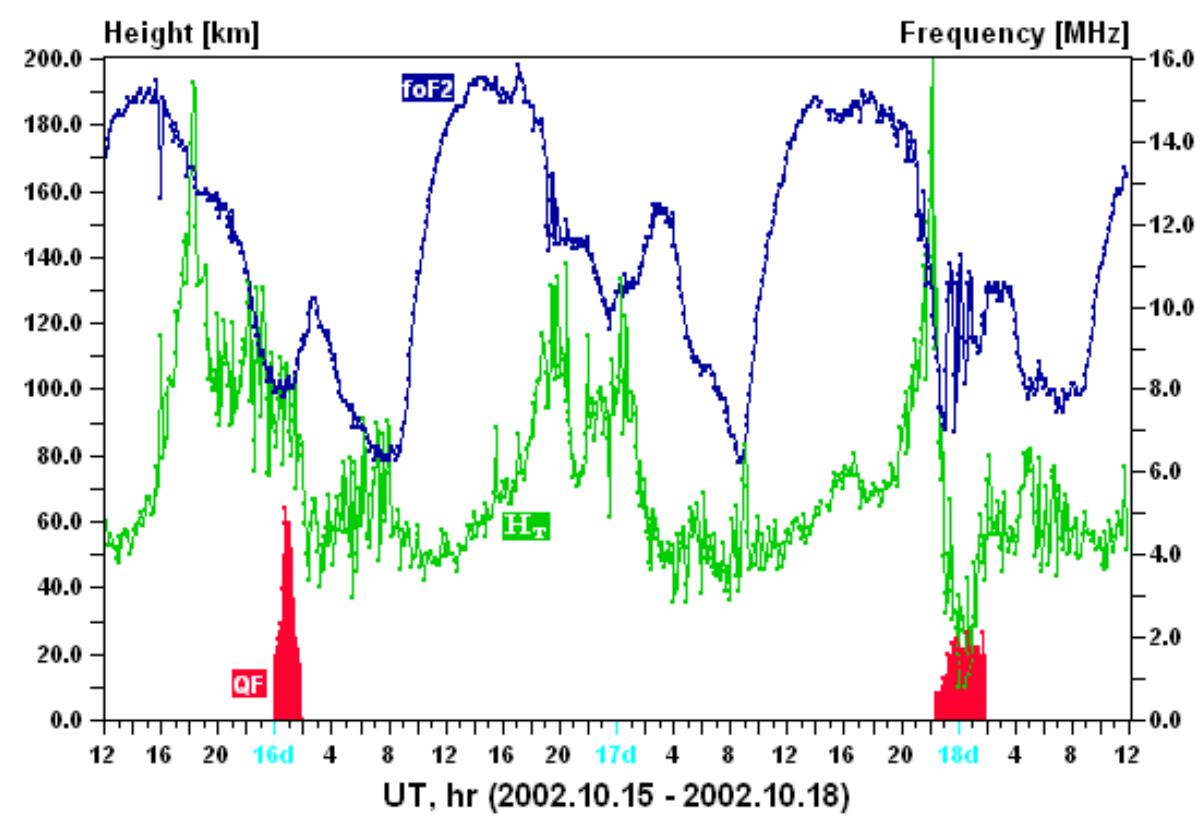

Fig. 7. Ionospheric characteristics as function of time at Cachimbo for three consecutive days in October 2002: foF2, topside scale height $\mathrm{HT}$, and range spread QF in $\mathrm{km}$. The vertical axis on the left shows the heights in $\mathrm{km}$, and on the right the frequencies in MHz.

\subsection{ADRES}

Automated Data Request Execution Subsystem (ADRES) is an integrated working environment capable of accepting a data request and taking the necessary steps to return the appropriate data, and also to remotely control the sounder schedule, data acquisition, alerting scalers, and generating the final report.

If the requested data are already in DIDBase and are validated, the ADRES generates the report immediately. A pro- vision is made to manage the requests for special modes of ionosonde operation (e.g. high ionogram rate during a satellite pass over the station, a coordinated campaign, or an event of interest) and for data that are not available in DIDBase or are not manually validated. The ADRES has a mechanism to automatically read incoming requests to adjust programs and schedules of the Internet-enabled digisondes. To acquire digisonde data, the ADRES maintains a list of FTP servers where the ionogram data can be found. A number of digisonde stations deliver their real time data directly to a 
WDC and to DIDBase. As soon as the data are ingested, a message is generated to the $\mathrm{SAO}-\mathrm{X}$ operators to validate/edit the autoscaling results. When the quality control procedure is completed, the final report is generated and delivered to the requesting party. Each step of the request execution is monitored, and the status of each request is available for remote access, just like any other data stored in the database.

Applications of the ADRES subsystem include the calibration and validation of space-borne UV sensors measuring ionospheric electron density profiles, and of the ionosondederived total electron content (ITEC) (Reinisch and Huang, 2001), by comparing it with the total electron content data from the TOPEX measurements. These campaigns provide a first opportunity to demonstrate the power of global ionosonde networking for quick access to ionospheric electron density distributions.

\section{Summary}

The establishment of a global Internet-connected digital ionosonde network with standardized data formats was the first gigantic step to make ionosonde data user-friendly. The new information system introduced in this paper was the missing second step. The new system, which includes the Digital Ionogram Data Base (DIDBase), the expert ionogram scaling tool "SAO Explorer", and the Automated Data Request Execution Subsystem (ADRES), provides organized freedom to ionogram data management and remote digisonde station control.

Acknowledgement. This work was in part supported by Air Force Contract No. AF19628-02-C-0092 and NASA Grant No. NAG513387.

\section{References}

Abdu, M. A., Batista, I. S., Reinisch, B. W., de Souza, J. R., de Paula, E. R., Sobral, J. H. A., and Bullett, T. W.: Equatorial Spread $\mathrm{F}$ and Ionization Anomaly Development as diagnosed from Conjugate Point Observation (COPEX) in Brasil, XXIII General Assembly of IUGG, Sapporo, Japan, 30 June-11 July, 2003.

Bibl, K. and Reinisch, B. W.: The Universal Digital Ionosonde, Radio Sci., 13, 519-530, 1978.
Conkright, R. O.: SPIDR on the Web: Space Physics Interactive Data Resource Online Analysis Tool, Proc. URSI XXVI GA, Toronto, Canada, 491, August 1999.

Conkright, R. O. and McNamara, L. F.: Quality control of automatically scaled vertical incidence ionogram data, Proc. Ionosph. Effects Symp. IES-96, 99-103, May 1996.

Galkin, I. A., Kitrosser, D. F., Kecic, Z., and Reinisch, B. W.: Internet access to ionosondes, J. Atmos. Solar-Terr. Phys., 61, 181186, 1999.

Gamache, R. R. and Reinisch, B. W.: Databasing of Scientific Data, Proceedings of the Workshop on Geophysical Informatics, Moscow, Russia, WDC-A Report UAG-99, 102-108, 1991.

Daniell, R. E., Brown, L. D., Anderson, D. N., Fox, M. W., Doherty, P. H., Decker, D. T., Sojka, J. J., and Schunk, R. W.: Parameterized Ionosphere Model: A Global Ionospheric Parameterization based on First Principles Models, Radio Sci., 30, 1499-1510, 1995.

Piggott, W. R. and Rawer, K. (eds.): URSI Handbook of Ionogram Interpretation and Reduction, 2nd edition, Report UAG-23, WDC-A for STP, NOAA, Boulder, Colorado, 1972.

Reinisch, B. W. and Huang, X.: Automatic Calculation of Electron Density Profiles from Digital Ionograms, 3, Processing of Bottomside Ionograms, Radio Sci., 18, 477, 1983.

Reinisch, B. W., Anderson, D., Gamache, R. R., Huang, X., Chen, C. F., and Decker, D. T.: Validating Ionospheric Models with Measured Electron Density Profiles, Adv. Space Res., 14, 12, 67-70, 1994.

Reinisch, B. W.: Ionosonde, in Upper Atmosphere, edited by Dieminger, W., Hartmann, G. K., and Leitinger, R., Springer, 370-381, 1996.

Reinisch, B. W.: Modern Ionosondes, in Modern Ionospheric Science, edited by Kohl, H., Ruster, R., and Schlegel, K., European Geophysical Society, 37191 Katlenburg-Lindau, Germany, 440-458, 1996.

Reinisch, B. W.: CHARS: URSI IIWG format for archiving monthly ionospheric characteristics, INAG Bulletin No. 62, WDC-A for STP, Boulder, CO, 38-46, 1998a.

Reinisch, B. W.: SAO (Standard ADEP Output) format for ionogram scaled data archiving, INAG Bulletin No. 62, WDC-A for STP, Boulder, CO, 47-58, 1998b.

Reinisch, B. W. and Huang, X.: Deducing Topside Profiles and Total Electron Content from Bottomside Ionograms, Adv. Space Res., 27, 1, 23-30, 2001.

Sojka, J. J., Thompson, D. C., Schunk, R. W., Eccles, V., Makela, J. J., Kelley, M. C., Gonzoles, S. A., Aponte, N., and Bullett, T. W.: Ionospheric data assimilation: recovery of strong mid-latitudinal density gradients, JASTP, 65, 2087-1097, 2003. 